Illinois State University

ISU ReD: Research and eData

Theses and Dissertations

$5-21-2015$

\title{
Music Therapy as Treatment for the Psychological Distress of Victims of Intimate Partner Violence: Comparing Expressive and Receptive Music Interventions
}

Kristiana Miner

Illinois State University, kristianaminer@gmail.com

Follow this and additional works at: https://ir.library.illinoisstate.edu/etd

Part of the Music Commons, and the Psychiatric and Mental Health Commons

\section{Recommended Citation}

Miner, Kristiana, "Music Therapy as Treatment for the Psychological Distress of Victims of Intimate Partner Violence: Comparing Expressive and Receptive Music Interventions" (2015). Theses and Dissertations. 418.

https://ir.library.illinoisstate.edu/etd/418

This Thesis is brought to you for free and open access by ISU ReD: Research and eData. It has been accepted for inclusion in Theses and Dissertations by an authorized administrator of ISU ReD: Research and eData. For more information, please contact ISUReD@ilstu.edu. 


\section{MUSIC THERAPY AS TREATMENT FOR THE PSYCHOLOGICAL DISTRESS \\ OF VICTIMS OF INTIMATE PARTNER VIOLENCE: \\ COMPARING EXPRESSIVE AND RECEPTIVE \\ MUSIC INTERVENTIONS}

Kristiana J. Miner

54 Pages

August 2015

Domestic violence or intimate partner violence refers to physical, sexual, or emotional harm committed by a current or former intimate partner. Intimate partner violence has varied and serious repercussions in the lives of its victims. The direct consequences of violence combined with the physical aftermath of emotional distress, fear, and anxiety can lead to a variety of ailments. Posttraumatic Stress Disorder and suicide are both major concerns for female victims of IPV. Considering that the issues faced by many victims of DV are pervasive and complex, treatment for survivors needs to be comprehensive and multifaceted. Music therapy is an evidence-based form of treatment that is well-suited for addressing the issues faced by victims of this type of abuse. This study focused on the use of music therapy in decreasing the distress levels of victims of intimate partner violence as well as comparing expressive and receptive music therapy techniques. The researcher hypothesized that expressive music therapy would be more effective in decreasing distress than receptive music therapy. In this study, a boardcertified music therapist (MT-BC) facilitated four music therapy sessions at domestic 
violence shelters. The group participants were women who were actively fleeing a threat of harm from a former or current intimate partner. Two of the sessions focused on expressive music therapy interventions and two sessions focused on receptive music therapy sessions. The participants $(N=13)$ were asked to rate their distress with an adapted form of the K6 distress scale before and after music therapy sessions. It was found that there were no significant differences in participants' distress levels whether they participated in expressive or receptive music therapy. Regardless of the questions or the type of therapy, distress scores significantly decreased from the pretest $(M=2.50, S E$ $=1.5)$ to the posttest $(M=1.80, S E=1.6)$, Wilk's $\Lambda=.37, F(1,11)=18.80, p=.001, \eta^{2}=$ .63 . 
MUSIC THERAPY AS TREATMENT FOR THE PSYCHOLOGICAL DISTRESS

OF VICTIMS OF INTIMATE PARTNER VIOLENCE:

COMPARING EXPRESSIVE AND RECEPTIVE

MUSIC INTERVENTIONS

KRISTIANA J. MINER

A Thesis Submitted in Partial Fulfillment of the Requirements for the Degree of

MASTER OF MUSIC

School of Music

ILLINOIS STATE UNIVERSITY

2015 
(C) 2015 Kristiana J. Miner 
MUSIC THERAPY AS TREATMENT FOR THE PSYCHOLOGICAL DISTRESS OF VICTIMS OF INTIMATE PARTNER VIOLENCE:

COMPARING EXPRESSIVE AND RECEPTIVE

MUSIC INTERVENTIONS

KRISTIANA J. MINER

COMMITTEE MEMBERS:

Andrea Crimmins, Chair

Cindy Ropp

David Snyder 


\section{ACKNOWLEDGMENTS}

I wish to thank Brian for his unending patience, support, and love. I could not have done this without you. Most importantly, Kaelynn: you are the best part of my life and the inspiration for my accomplishments. I would also like to thank my graduate colleagues for their friendship and support.

I would like to express my gratitude to Andrea Crimmins, Assistant Professor at Illinois State University. Thank you for providing your guidance and expertise as I pursued a subject about which I am very passionate. I would also like to thank Cindy Ropp, Associate Professor at Illinois State University for her feedback and also for being a supportive mentor for all these years. My thanks also goes to David Snyder, Professor at Illinois State University for feedback that greatly improved the manuscript. My gratitude goes to J.D. Hogue as well, whose expertise as a colleague and influence as a friend were enormously helpful in this study.

This research was supported by The Center for Prevention of Abuse. I am immensely grateful to Sara Dillefeld, Director of Domestic Violence Family Centered Services, Teresa Markum, Family Centered Domestic Violence Counselor, and Heather Burke, Domestic Violence Family Counselor for their feedback and encouragement. I would also like to express my gratitude for the women who participated in my study. They opened their hearts to me, shared their thoughts, and supported my academic endeavors. 


\section{CONTENTS}

Page

ACKNOWLEDGMENTS $\quad$ i

CONTENTS

TABLES $\quad$ iv

CHAPTER

I. INTRODUCTION AND BACKGROUND 1

Introduction: The Problem of Domestic Violence 1

What is Domestic Violence? 1

Forms of Intimate Partner Violence $\quad 2$

$\begin{array}{ll}\text { Hypotheses and Purpose } & 7\end{array}$

Definition of Terms $\quad 8$

$\begin{array}{ll}\text { Limitations of the Study } & 8\end{array}$

II. INTIMATE PARTNER VIOLENCE: REVIEW OF RELATED

$\begin{array}{ll}\text { LITERATURE } & 10\end{array}$

The Repercussions of Intimate Partner Violence 10

Treatments for Victims of Intimate Partner Violence 14

$\begin{array}{ll}\text { Music Therapy as Treatment } & 16\end{array}$

Limitations of Related Studies $\quad 21$

Summary 22

$\begin{array}{ll}\text { III. RESEARCH DESIGN } & 24\end{array}$

Addressing Intimate Partner Abuse 24

$\begin{array}{ll}\text { Method } & 24\end{array}$

$\begin{array}{ll}\text { Participants } & 24\end{array}$ 
Sampling Procedures $\quad 25$

Research Design $\quad 25$

$\begin{array}{ll}\text { Measures } & 27\end{array}$

$\begin{array}{ll}\text { Procedures } & 28\end{array}$

IV. ANALYSIS OF THE DATA 30

Hypotheses and Purpose $\quad 30$

Results $\quad 30$

Preliminary Analyses $\quad 30$

Primary Analyses $\quad 32$

$\begin{array}{ll}\text { Summary } & 38\end{array}$

$\begin{array}{ll}\text { V. SUMMARY, CONCLUSIONS, AND } & 39 \\ \text { RECOMMENDATIONS } & \end{array}$

$\begin{array}{ll}\text { Summary } & 39\end{array}$

Discussion $\quad 39$

Discussion of Study Results $\quad 39$

Addressing the Limitations of Related Studies 44

How These Results Affect Clinical Practice in Music Therapy 44

How These Results Apply to the General Needs of This Population 46

Recommendations for Further Research 47

$\begin{array}{ll}\text { REFERENCES } & 49\end{array}$

APPENDIX A: Adapted K6 Distress Scale 53

APPENDIX B: Music Therapy Research Study Consent Form 54 


\section{TABLES}

Table Page

1. Participants' Ages and Length of Current Stay at Domestic Violence Shelter

2. Music Therapy Conditions and Participants' Ethnic/Cultural Backgrounds 31

3. Means and Standard Deviations of PreK6 and PostK6 Scores 32

4. Comparisons Between Individual Items on the Adapted K6 Questionnaire

5. Type of Therapy and Pretest/Posttest 34

6. Type of Therapy and the Individual Questionnaire Items 35

7. Pretest/Posttest and the Individual Questionnaire Items 36

8. Three-Way Interaction 37 


\section{CHAPTER I}

\section{INTRODUCTION AND BACKGROUND}

\section{Introduction: The Problem of Domestic Violence}

The American Psychological Association (2014) states that more than one out of three women in the United States experience violence, sexual assault, and/or stalking at the hands of an intimate partner. Beyond the physical violation, these women usually experience a level of emotional abuse as well as the psychological effects of being battered. Not all women survive their attacks, and those who do are often left grappling with both physical and psychological repercussions of their abuse.

It may surprise some, but some researchers state that the emotional aftermath of abuse is worse than the physical effects (Kelly \& Johnson, 2008). Distress may be especially significant for women who have recently experienced violence or the threat of violence and fled to a shelter.

\section{What is Domestic Violence?}

The terms domestic violence (DV) and intimate partner violence (IPV) are often used interchangeably. Both terms refer to the physical, sexual, or emotional harm committed by an intimate partner, whether current or former (National Institute of Justice, 2007; U.S. Department of Justice, n.d.; Whipple \& Lindsey, 1999). IPV is a prevalent problem in the United States, with more than one out of three women and more 
than one out of four men experiencing violence, sexual assault, and/or stalking at the hands of an intimate partner (American Psychological Association, 2014). Tjaden and Thoennes (2000) estimate that in the United States, approximately 1.5 million women and 834,732 men have been raped and/or physically assaulted by an intimate partner.

\section{Forms of Intimate Partner Violence}

There are various forms of IPV. Any combination of them may occur. Domestic violence may include types of abuse such as physical violence, sexual violence, threats of physical/sexual violence, psychological/emotional violence, and stalking (National Institute of Justice, 2007; U.S. Department of Justice, n.d.). Abusers use these behaviors in order to "intimidate, manipulate, humiliate, isolate, frighten, terrorize, coerce, threaten, blame, hurt, injure, or wound someone” (U.S. Department of Justice, n.d., para. 1).

When people think of domestic violence, they usually think of its most obvious sign: physical abuse. This form of abuse can involve "hitting, slapping, shoving, grabbing, pinching, biting, hair pulling" (U.S. Department of Justice, n.d., para. 2) and may manifest itself in black eyes, broken bones, burst eardrums, burning, scalding, broken teeth, strangulation, and bruising (Nevada Network Against Domestic Violence [NNADV], 2012, p. 4). Beyond actively causing harm to someone, certain types of neglect can also be seen as physical abuse. An abuser can deny his or her victim needed medical care and/or medications (U.S. Department of Justice, n.d.). The abuser's behavior is intentional and the violence often escalates over time in both frequency and severity (NNADV, 2012). 
Physical mistreatment is just one of the many forms of IPV. Sexual abuse can also be used by an abuser against a victim. According to the U.S. Department of Justice (n.d.), sexual abuse is "coercing or attempting to coerce any sexual contact or behavior without consent" (para. 3). Sexual abuse includes marital rape, attacking sexual areas of the body, forcing sex after physical assault, or demeaning/humiliating someone sexually (U.S. Department of Justice, n.d.). Coker, Smith, McKeown, and King (2000) surveyed 1,401 participants and found that a number of them had experienced sexual violence: 7.7 percent of the women currently involved in a relationship, and 17.7 percent in their most recent relationship.

Abusers often also take control of their victim's finances. The U.S. Department of Justice (n.d.) defines economic abuse as "making or attempting to make an individual financially dependent by maintaining total control over financial resources, withholding one's access to money, or forbidding one's attendance at school or employment" (para. 5). This serves the abuser's purpose - to be in control of the victim.

Victims of coercive violence (such as what is found in IPV situations) often report that the psychological ramifications of what they suffered was worse than the actual physical violence (Kelly \& Johnson, 2008) and that "constant exposure to beatings is also damaging mentally in terms of that individual's self-esteem, self-worth, and selfconfidence" (The Nevada Network Against Domestic Violence, 2012, p. 4). Tjaden and Thoennes (2000) found that violence is often accompanied by emotional abuse and controlling behaviors, and that verbal abuse is the most likely predictor of violence between intimate partners, especially when combined with a systematic pattern of dominance and control (Tjaden \& Thoennes, 2000). In a study involving 1,401 female 
participants, Coker, Smith, McKeown, and King (2000) found that "more than one third of the violence assessed in a current or most recent relationship was classified as nonphysical psychological battering" (p. 558).

Abusers often manipulate their victims through psychologically and emotionally abusive techniques. These may be categorized as: verbal attacks, isolation, jealousy or possessiveness, verbal threats, emotional blackmail, and/or damage/destruction of victim's personal property (Follingstad et al., 1990). Often, perpetrators of IPV will sabotage a victim's relationship to loved ones and friends, call the victim demeaning names, or diminish his or her abilities in order to undermine the victim's sense of selfworth (U.S. Department of Justice, n.d.) and make the victim believe that he or she is worthless (Follingstad et al., 1990). They may threaten to physically harm themselves, the victim, the victim's children, or the victim's other loved ones (including pets). They may also force isolation and not allow the victim to see friends or family, attend school, or go to work (U.S. Department of Justice, n.d.). While Follingstad et al. (1990) stated that some research has found that "there is no systematic, empirical documentation to currently substantiate any relationship between types of emotional abuse and patterns of physical violence" (p. 108), the effects of psychological abuse may be part of a cycle of violence which leaves the victim feeling trapped.

Intimate partner abuse often occurs in a cycle and thus usually involves repeat victimization. For example, Tjaden and Thoennes (2000) report that of women who were raped by their intimate partner, 51.2 percent reported repeat victimization, suffering from an average of 4.5 rapes over an average of 3.8 years. Of the women who reported being physically assaulted by their intimate partner, 65.5 percent stated that they were 
repeatedly attacked, suffering from an average of 6.9 assaults over an average of 4.5 years. Similar statistics were seen for male victims of domestic violence. Over 66 percent of male victims reported that they were assaulted multiple times. However, the average frequency and duration of intimate partner violence committed against women were found to be higher than IPV committed against men (Tjaden \& Thoennes, 2000). Domestic violence can happen to anyone, anywhere (U.S. Department of Justice, n.d.). The abuse can also occur at the hands of a current or former partner. This type of violence is not limited to certain socioeconomic backgrounds, education levels, same-sex or opposite-sex relationships, or the marital status of the persons involved (National Institute of Justice, 2007; U.S. Department of Justice, n.d.).

However, there are different rates of IPV experienced by certain populations. Pregnant female victims are especially vulnerable, as IPV is the "leading cause of female homicides and injury-related deaths during pregnancy" (APA, 2014, p. 1). In fact, regardless of whether same-sex or opposite-sex intimate partnerships are being considered, women are significantly more likely to experience IPV than men. Not only are the numbers greater, but their victimization may last longer and can result in more severe injuries (Tjaden \& Thoennes, 2000). Unmarried couples are also at greater risk than married couples (Tjaden \& Thoennes, 2000). Ethnicity also has an effect. Data on women and individuals of racial/ethnic minorities show higher lifetime rates of rape, physical violence, and stalking by an intimate partner (Center for Disease Control and Prevention, National Center for Injury Prevention and Control, Division of Violence Prevention. [CDC], 2010). Black non-Hispanic women and multiracial non-Hispanic women are significantly more likely than White non-Hispanic women to experience rape, 
violence, or stalking by an intimate partner. American Indian and Alaskan Native people experience a higher rate of IPV, while Asian/Pacific Islander non-Hispanic women are significantly less likely to have experienced these forms of abuse (CDC, 2010; Tjaden \& Thoennes, 2000). While victims of IPV may be of any age, statistics show that the abuse tends to begin during teenage or young adult years (CDC, 2010). Women with disabilities have been found to have a 40 percent greater risk of being victimized by an intimate partner as well as experiencing especially severe violence (APA, 2014). There may also be a link between child maltreatment and intimate partner violence. Both men and women with a history of being abused as children at the hands of their caregivers were significantly more likely to report being abused by a current partner. There are various explanations for this. One possibility is that there are higher reporting rates because people who were victimized as children are more likely to continue living with violence as adults and are more likely to become involved in an abusive relationship. Another possibility is that people who are willing to report that they were victims of child abuse are also more open to report other forms of abuse (Tjaden \& Thoennes, 2000).

The most dangerous time for victims of IPV is when they attempt to leave the abusive relationship (NNADV, 2012). The data supports this idea, though there is a debate about whether the separation triggers the violence or vice versa. Married female victims of IPV who are separated from their husbands are four times more likely to report that their husbands had raped, physically assaulted, and/or stalked them than married female victims of IPV currently living with their spouses (Tjaden \& Thoennes, 2000). Block (2003) found that 45 percent of the murders of women by their intimate partners were precipitated by the women's attempt to leave. 


\section{Hypotheses and Purpose}

Music therapy is an evidence-based, holistic, and adaptable form of therapy that can simultaneously address mind, body, and emotions. Victims of intimate partner violence are often left dealing with psychological, physical, and emotional issues due to

the abuse they have experienced. As such, it is a viable form of treatment for women who have suffered domestic violence.

The purpose of this study is to investigate whether or not participating in music therapy interventions that involve music-making (such as actively expressing themselves in instrumental or vocal music) or participating in music therapy interventions that that are primarily receptive (such as engaging in music-facilitated relaxation) produce different effects on the psychological distress of women living in a battered women's shelter.

It is evident from the literature that victims of IPV may be suffering in a multitude of ways - physically, emotionally, and psychologically. It is also evident that victims of IPV have a high chance of experiencing psychological distress from the violence they have experienced. Music therapy has been shown to help increase relaxation, provide an emotional outlet while decreasing stress and anxiety. It is hypothesized that expressive music therapy interventions (i.e. active music making) will be more effective in decreasing distress levels when compared to receptive music therapy interventions (e.g. music facilitated relaxation or lyric analysis). 


\section{Definition of Terms}

Throughout this study, the terms domestic violence (DV) and intimate partner violence (IPV) are used interchangeably. Both terms refer to abuse suffered at the hands of a current or former intimate partner.

The terms expressive music therapy intervention and receptive music therapy intervention are operationally defined here and used throughout this study, but it is understood that music therapy inherently involves active engagement in music regardless of whether or not participants are making or listening to music. For the purpose of this study, expressive music therapy intervention refers to music-making, whether vocal or instrumental. Receptive music therapy intervention refers to engaging in music without active music-making. The participants who experienced receptive MT interventions took part in music-facilitated deep breathing and progressive muscle relaxation exercises.

\section{Limitations of the Study}

This study had a number of limitations. The number of participants was far smaller than originally planned due to time constraints and the number of music therapy sessions that were allowed to be facilitated at the battered women's shelters. Also, in order to keep the clients' identities completely confidential and anonymous, no identifiers were gathered in the questionnaire. Though each participant received an informed consent document they were not required to sign it. There were a few repeat participants who received both the expressive and receptive music therapy treatments. It would have been very interesting to be able to track repeat participants and analyze differences between their exposures to both types of music therapy. Considering that there are not 
many studies that focus on music therapy with this population, this study contributes to the evidence in support of music therapy as a treatment. 


\section{CHAPTER II}

\section{INTIMATE PARTNER VIOLENCE: REVIEW OF RELATED LITERATURE}

\section{The Repercussions of Intimate Partner Violence}

Intimate partner violence is recognized in the U.S. as a "significant health problem" with "many negative impacts and long-term health consequences"(CDC, 2010, p. 1). Compounding the issue is the realization that IPV does not just affect the person against whom the violence is directed. In Hong Kong, researchers found that children exposed to childhood abuse and neglect and parental intimate partner violence reported lower levels of self-esteem and higher rates of violence and feeling threatened (Chan, Brownridge, Yan, Fong, \& Tiwari, 2011). Considering all the factors mentioned above, the problem of IPV is daunting. When broaching the subject of preventing IPV, it is understandable that it "requires reaching a clear understanding of those factors, coordinating resources, and fostering and initiating change in individuals, families, and society" (National Institute of Justice, 2007, para. 2).

Intimate partner violence has varied and serious repercussions in the lives of its victims. Victims of IPV quite literally fear for their lives. Block (2003) found that, frighteningly, one in five women killed or severely injured by an intimate partner had no warning. It was the first physical violence they had experienced from their partner. For 
victims that survive their first violent encounter with a partner, the direct consequences of violence combined with the physical aftermath of emotional distress, fear, and anxiety can lead to a variety of ailments. Female victims of IPV have been found to be more likely to report ailments such as asthma, irritable bowel syndrome, diabetes, and poor mental health compared to women who did not experience these forms of violence (CDC, 2010). Men and women who have experienced a lifetime of intimate partner abuse are more likely to complain of poor physical health in general compared to those who have not experienced IPV. Overall, IPV can cause "immediate and long-term health, social, and economic consequences" (The National Institute of Justice, 2007, para. 2).

Victims of IPV may also experience serious and pervasive issues with their mental health, especially the areas of depression, posttraumatic stress disorder (PTSD), and suicidality. In Golding's (1999) meta-analysis of 18 studies, the prevalence of mental health issues (especially depression, suicidality, PTSD, alcohol abuse or dependence, and drug abuse or dependence) is much higher among women who have experienced domestic violence than in the general population of females. In fact, "the percentage of women who consider their mental health to be poor is almost three times higher among women with a history of violence than among those without" (APA, 2014, p. 1). Goodwin, Chandler, and Meisel (2004) found that nearly half of the women who reported serious intimate partner violence meet criteria for major depression, 24 percent suffer from PTSD, and 31 percent suffer from anxiety. Among female DV survivors, Golding (1999) found that PTSD diagnoses occurred at a mean rate of 63.8 percent due to the high levels of anxiety, hyperarousal, and sleep disturbances (Goodwin, Chandler, \& Meisel, 2004; Hernández-Ruiz, 2005). Suicide is a major concern when it comes to female 
victims of IPV. Battered women had a 17.9 percent rate of suicidality, while only 0.8 percent to 15.9 percent of the general population experiences suicidal ideation and 0.1 percent to 4.3 percent actually attempts suicide (Golding, 1999).

The consequences of IPV in a victim's life are not limited to just physical injury and emotional wounding. The cost of medical care can be financially debilitating. IPV victims may be facing bills for emergency room visits, physician appointments, physical therapy, dental care, ambulance or paramedic services, hospital overnights, and outpatient visits (Centers for Disease Control and Prevention, 2003). Also, the victim could possibly miss several days of work and face the very real possibility of losing his or her job. If children are involved, the victim could also be struggling to find affordable childcare. The cost of intimate partner violence is believed to be over $\$ 5.8$ billion per year, $\$ 4.1$ billion of which is the direct cost of medical care and mental health services. Of the 5.3 million intimate partner victimizations that occur among adult U.S. women, there are almost 1,300 deaths and more than 555,000 victims require medical services, with more than 145,000 victims with injuries serious enough to warrant hospitalization for at least one night. Also to be considered are IPV victims' 18.5 million mental health care visits per year, with 13.6 million days of lost productivity from work and household chores (CDC, 2003).

The most extreme response in the face of extreme violence is that of homicide. When faced with the choice of fight or flight, some victims may choose to fight. Kelly and Johnson (2008) identify this response as the type committed by victims "who feel trapped in a relationship with a coercively controlling and violent partner" (p. 485). The victims who choose to combat the violence with further violence are most likely to have 
experienced the most severe abuse, whether judging by frequency and/or brutality, as well as many types of abuse, leaving them feeling helpless and trapped (Kelly \& Johnson, 2008). They may be seen as people who were pushed to their limits, who "felt that they could no longer survive in this relationship and that leaving safely was also impossible," or they reacted in response to a direct threat against their child (Kelly \& Johnson, 2008, p. 485). Sadly, these victims may have turned to the authorities several times and not received help.

In the midst of such extreme mistreatment, where can victims go for help? People tend to be more trusting of loved ones and friends. The CDC (2010) reports that among IPV victims, 84 percent of females and 61 percent of males disclosed the abuse to someone close to them, such as a family member or friend. Only 21 percent of females and 6 percent of men disclosed to medical staff. For many victims of IPV, law enforcement is the first entity they turn to for help. However, underreporting is a serious concern with this population. Tjaden and Thoennes (2000) found that only 17.2 percent of women who were raped by their intimate partner reported the assault to the police. They also found that these victims chose not to report to law enforcement due to fear of retaliation (21.2 percent), seeing the assault as a minor incident (20.3 percent), feelings of shame and a desire for privacy (16 percent), and/or the belief that the police could not accomplish anything (13 percent). The last item is an unfortunate reality in cases such as these. There are very low rates of criminal prosecution of attackers in domestic violence situation. Of women who reported being raped by an intimate partner, only 7.5 percent actually saw their attacker criminally prosecuted. Similar rates can be found for women who were physically assaulted (7.3 percent) (Tjaden \& Thoennes, 2000). The victim's 
experience with the justice system affects their ability to deal with the trauma of violence. Victims who perceive higher levels of procedural justice tend to experience higher levels of quality life, lower levels of depression, and higher levels of intention to use the court system again, regardless of case disposition (Calton \& Cattaneo, 2014, p. 1 abstract).

\section{Treatments for Victims of Intimate Partner Violence}

There are few evidence-based treatments that have been evaluated and shown to be effective when it comes to domestic violence (Miller, Howell, \& Graham-Bermann, 2014). Clinicians must help establish the victim's sense of safety before any therapeutic progress can be accomplished. It is helpful to focus on the symptoms of trauma, not the actual traumatic event. Recalling the traumatic incident(s) themselves may be triggering to the survivor, to the listeners, and (in a group setting) could result in the fragmentation of the group (Borczon, Jampel, \& Langdon, 2010). Part of establishing a sense of safety is establishing trust between the clinician and the client. However, when someone has experienced violence at the hands of a loved one, this trust can be difficult to establish (Peck, 2012).

Beyond establishing a sense of safety, empowering the survivor is also vital for healing. Many researchers believe that treatment should focus on empowerment (Herman, 1998; Whipple \& Lindsey, 1999). Perpetrators of IPV are known for asserting their control over their victims. They manipulate their victims through physical brutality and psychologically demeaning treatment. This leaves the victims feeling powerless. Some clinicians have recommended that the recovery process should be based on "empowerment of the survivor and restoration of relationships" with a three-stage 
recovery process: "establishing safety, retelling the story of the traumatic event, and reconnecting with others" (Herman, 1998, abstract).

An essential part of recovery from IPV is that of interpersonal connection. Most people agree that one way to counter IPV is to combat isolation (a common tool used by abusers) through strong support systems (Jewkes, 2002; Kelly \& Johnson, 2008; NNADV, 2012). Abusers may utilize isolation to keep their victim under control and in the relationship, and victims of IPV may feel isolated by feelings of shame or embarrassment. Herman (1998) states that "recovery can take place only within the context of relationships; it cannot occur in isolation" and that the victim needs "renewed connections with other people" in order to restore "basic capacities for trust, autonomy, initiative, competence, identity, and intimacy" (Herman, 1998, p. S145). Seligman (2008) supports the use of interventions that are centered on happiness (Seligman, Parks, \& Steen, 2004).

Some clinicians use a combination of forgiveness therapy and alternative treatment (anger validation, assertiveness, interpersonal skill building) for emotionally abused women who have been permanently separated from their abusive intimate partner. Using this technique, IPV survivors may see significant improvement in many areas of mental health, including depression, anxiety, posttraumatic stress symptoms, self-esteem, forgiveness, environmental mastery, and finding meaning in life (Reed \& Enright, 2006). Some interventions that were found to be helpful were ones that made use of creative arts (e.g. clay work, drawing, journaling) with music as well as music-based relaxation/breath centering (Teague, Hahna, \& McKinney, 2006). Stockton and Hunt (2014) found that 
creative writing helped the 24 participants in their study process and experience increased posttraumatic growth, with language analyses showing greater use of insight words.

\section{Music Therapy as Treatment}

Cassity and Theobold (1990) found that of the 2,564 active, registered, and certified music therapists in the U.S. at the time, 80 stated that they worked with victims of domestic violence. Many of these music therapists worked with people who experienced domestic violence in different ways: 45 indicated that they worked with female victims of IPV, 61 indicated that they worked with the children of female victims of IPV, and 28 indicated working with male abusers. According to Silverman (2007), about 21 percent of board-certified music therapists work in the mental health field and use music therapy "to teach patients about their illnesses and medications, about healthy coping and leisure skills, and to increase insight. It can also function as a method of bringing patients together to address socialization and communication goals" (Silverman, 2007, p. 389).

As an evidence-based, multi-faceted treatment provided by a credentialed professional, music therapy (MT) could be an effective treatment for the variety of issues faced by victims of IPV. Borczon et al. (2010) identifies improvisation, composition, lyric analysis, and music and imagery as effective music therapy treatments for people who have experienced trauma. One music therapy technique that has been used with people who have gone through traumatic experiences is that of "re-scripting" nightmares through the use of music (Borczon et al., 2010, p. 51). This could be especially useful as recurrent nightmares are a symptom of people with PTSD, and victims of IPV have been 
identified as especially susceptible to the development of PTSD (Hernández-Ruiz, 2005). Re-scripting nightmares involves having the client recall a nightmare that he or she had, or imagining a nightmare situation. The client then creates music that reflects that nightmare image. The client is also asked to think of an ideal dream situation or what happiness would look like to them. They also create music that reflects that image of happiness. The MT-BC and client work together to create a musical composition consisting of the music of both images in harmony together.

Music in storytelling is another music therapy technique that could possibly be helpful for survivors of domestic violence. Because a survivor's self-image and life story may be so altered by trauma, music may be used to create "a story that resonates or reflects the inner needs and wisdom of the client can be activated and brought to consciousness" (Borczon, Jampel, \& Langdon, 2010). The opportunity for selfexpression through music could be invaluable for the healing and treatment of an IPV survivor.

Music therapy has been shown to be effective in addressing mental health issues that could be a concern for IPV survivors. Hernández-Ruiz (2005) found the use of MT shown to have a positive effect upon anxiety levels and sleep patterns of women living in a battered women's shelter. Reducing anxiety and helping regulate sleep patterns increased the resources of the shelter residents. MT has also shown to help significantly decrease the perceived levels of anxiety in a variety of populations (Hernández-Ruiz, 2005). In Teague's (2006) study of seven participants in six weekly MT sessions, it was found that MT only provided a marginally significant decrease in anxiety. However, it did provide a significant decrease in depression. Whipple and Lindsey (1999) performed 
a study involving fifteen women temporarily residing in a battered women's shelter. The participants attended eight weekly MT group sessions that were centered on goal setting skills, communication, mood elevation, and self-esteem (Whipple \& Lindsey, 1999). Coffman and Adamek (1999) found that people who participated in social, music-making settings found that their needs for a sense well-being and accomplishment were met. Music therapy in a counseling setting was found to be effective (Whipple \& Lindsey, 1999). Various song-writing techniques (fill-in-the-blank scripts, group song writing, improvisational song writing, discharge song writing) were found to help empower adolescents who have experienced traumatic injury (Robb, 1996).

There have been several types of studies done exploring the use of MT with victims of intimate partner violence. A variety of surveys have been distributed in a variety of forms, including phone interviews (Follingstad, Rutledge, Berg, Hause \& Polek, 1990), questionnaires (Coffman \& Adamek, 1999), and online surveys (Stockton \& Hunt, 2014). Some studies were more long term. For example, in the longitudinal study by Beeble, Bybee, Sullivan, and Adams (2009), 160 survivors of IPV were interviewed 6 times over the course of 2 years to see how social support affected their well-being. Some studies were more short-term, such as the Whipple \& Lindsey (1999) study in which they surveyed fifteen females temporarily residing in shelter during in 8 weekly MT group sessions.

Verbal processing and self-expression are valuable parts of healing for this population. Music therapy in a counseling setting was found to be effective (Nolan, 2005; Whipple \& Lindsey, 1999). Various song-writing techniques (fill-in-the-blank scripts, group song writing, improvisational song writing, discharge song writing) were found to 
help empower adolescents who have experienced traumatic injury (Robb, 1996). Nolan (2005) addressed both expressive and receptive music therapy in his study of verbal processing in music therapy. He supported the use of verbal processing in music therapy sessions to keep groups therapeutically focused, shifts ego states, heightens social connectivity between clients, enhances reality testing, and provides the music therapist with more opportunities for evaluating client states.

Looking at studies that specifically target a comparison between expressive and receptive music therapy, there is only one that focused on the population of domestic violence. In the Cassity and Theobold (1990) survey of professional music therapists, many of the music therapists differentiated between verbal (lyric analyses, singing) and nonverbal (instrumental improvisation, movement) interventions. According to their study, the majority of music therapists working with victims of domestic violence noted that attention deficit behaviors were a common issue. Most of the music therapists refocused the clients through involving them in music making, suggesting active instrument performance as an effective way to redirect clients for an extended period of time. Victims of domestic violence are often also sexually assaulted by their abusers. Amir (2004) conducted a study focusing on improvisational music play as part of treatment for people who have experienced sexual abuse. The study supports the idea of using music improvisation as a way to "bring out hidden, unconscious material and make it conscious and available to the client" (p. 96). Amir (2004) supports the use of psychoanalytic exploration of the improvisation experience, which admittedly "depends on the mental, cognitive, and emotional state of the client, on the mount of trust she has in the therapist, and in her motivation and readiness to do this kind of work" (p. 98). 
Some researchers working with other populations have found that expressive music therapy (as defined by this study) has been helpful in addressing a variety of medical needs. Research by Takahashi and Matsushita (2006) suggested that instrument play and singing was helpful in preventing cerebral and cardiac diseases. In a study of immune function and musical activity, Kuhn (2002) found that "musical activity can increase immune system function within the mouth which is the first line of defense against pathogens of the upper respiratory tract” (p. 36).

There are some researchers who have compared expressive and receptive music therapy with populations experiencing behavioral, mental health, and psychological issues. When comparing "active, 'music-making"” interventions and "passive, 'music listening"' interventions (p. 50), Montello and Coons (1998) found that music-making and music-listening interventions were beneficial for children with emotional, learning, and behavioral disorders. On the other end of the age spectrum, a study by Hanson, Gefeller, Woodworth, Swanson, and Garand (1996) examined the use of expressive music therapy interventions with older adults with Alzheimer's disease. They found that participants at varying levels of cognitive functionality appeared to "respond more purposefully to both rhythm and singing activities when those types of activities were designed to be less demanding" (p. 120). Nolan (2005) examined expressive and receptive music therapy combined with verbal processing and supports the use of verbal processing with both types of music therapy. 


\section{Limitations of Related Studies}

Domestic violence is not addressed nearly as much as other subjects in music therapy literature. There are studies and information about music therapy in treating trauma, but victims of intimate partner violence have suffered a specific type of trauma and often have unique combinations of issues. Also, the studies reviewed here have shown a lack of data concerning the effects of treatment in acute settings. There is a deficiency in information about of how music therapy could affect IPV/DV victims in an acute setting.

There was only one example of music therapy literature that focused specifically on comparing expressive music therapy interventions with receptive music therapy interventions when working with victims of domestic violence (Cassity and Theobold, 1990). There are many studies in music therapy literature that contrast expressive and receptive music therapy with a variety of populations. In older music therapy literature, it appears that this concept is referred to as active music therapy and passive music therapy. As music is a form of therapy that requires active engagement of participants, such terminology is not quite accurate. It was decided that for this study, the terms expressive music therapy and receptive music therapy would be operationally defined and used. Even though the individual studies may not address domestic violence or expressive/receptive music therapy specifically, they may still provide insight in related areas. Still, there is a need for studies that look at expressive and receptive music therapy interventions with this specific population.

This study will compare expressive and receptive music therapy interventions and their effect on intimate partner violence victims' level of distress in an acute setting. 
Distress is a common and understandable issue faced by many victims of domestic violence, especially for those who have recently fled their abusive partners due to threat of harm. The data gathered in this study will help address an area of need within the world of music therapy literature.

\section{Summary}

Intimate partner violence is abuse caused by a current or former sexual partner. There are many different forms of it, including physical mistreatment, financial abuse, psychological/emotional abuse, and sexual assault. Victims of IPV may be left dealing with many devastating repercussions of the abuse, both direct and indirect. The physical harm brought on by the violence is often combined with a variety of mental health issues (often with physical consequences of their own). Treating all of these issues is not cheap, and victims may find themselves financially drained.

Treatments for survivors of IPV are varied. A few essentials include establishing a sense of safety, focusing on empowering the victim, and encouraging interpersonal connection. While many music therapists work in the mental health arena, not many have worked specifically with victims of IPV. There is some literature about music therapy as a treatment for trauma. Some music therapy techniques discussed in the literature includes instrumental improvisation, composition, lyric analyses, "re-scripting" nightmares through music, and utilizing both expressive and receptive music therapy techniques combined with verbal processing.

There have been several studies used to explore the use of music therapy with the victims of intimate partner violence (though not nearly as many as those for other 
populations). Of those, only one specifically focuses on comparing expressive and receptive music therapy with this population. The results from this study will help to add to the pool of knowledge about music therapy. 


\section{CHAPTER III \\ RESEARCH DESIGN}

\section{Addressing Intimate Partner Abuse}

In order to focus on the distress levels of people who have experienced intimate partner abuse, an agency in the central Illinois area that specialized in addressing domestic violence and sexual assault was contacted. The agency provided the opportunity to facilitate music therapy sessions at two of their domestic abuse shelters. These shelters housed adult women and their children who were fleeing from an active threat of harm from a current or former intimate partner. Due to their experiences, these residents provided an optimal participant pool for the purposes of this study.

\section{Method}

\section{Participants}

Thirteen women completed the study. The average age was 30.56 years $(S D=$ 9.66), and they spent an average of 13 days $(S D=11.40)$ at the shelter. Most of the participants (46\%) were Caucasian, but the rest were African American (31\%) and Biracial (15\%). Six people received the expressive music therapy condition, and seven people received the receptive music therapy condition.

Participants in this study $(N=13)$ were individuals living at the study sites (two battered women's shelters located in the Midwestern region of the U.S.). In order to be 
allowed to live at the shelter, the residents must be adult women over the age of eighteen who are actively fleeing from immediate threat of harm due to an abusive relationship. Length of stay at both sites varies on an individual basis and can range from less than twenty-four hours up to a maximum of six weeks. Participants were gathered from the population of the adult females living in these shelters. Children of these women under the age of 17 may also stay at the shelter with their mothers, but the facilities' group meetings are limited to just the adult women. The monthly music therapy groups were held during the regular group meeting time. The shelter residents who would have attended the regular group counseling session at those times attended the music therapy groups.

\section{Sampling Procedures}

This study utilized a sample of convenience, as the setting was structured in such a way that made random assignment impossible. Participants were adult women over the age of 18 living in women's shelters in the Midwest region of the United States due to fleeing from an immediate threat of harm. These women were in the midst of attending weekly group sessions who chose to take part in the study.

\section{Research Design}

Prior to this study, four music therapy sessions were facilitated by the MT-BC at both of the sites for a total of eight music therapy sessions with this population. This allowed the MT-BC to gain clinical experience working with this specific population before actually conducting the study. Considering that the literature points out very 
specific needs with the domestic violence population, it was helpful to gain insight in this area. For example, a song ("Three Things" by Jason Mraz) used during the first few sessions appeared to be triggering to some group members. The emotional reaction to the song was so distracting that it resulted in the splintering of the group dynamic. The MT$\mathrm{BC}$ found it difficult to redirect the group members to focus on therapeutic outcomes. Rewriting the lyrics to the song did not appear to help the loss of therapeutic focus. In the end, the song was dropped from the sessions and "I Am a Rock" by Simon and Garfunkel was substituted as the focus for lyric analysis exercises.

For this study, one monthly group music therapy session was facilitated per site for a total of four music therapy sessions. Data was gathered from questionnaires administered before and after each session. The music therapy sessions alternated structures in $\mathrm{ABAB}$ form with each session consisting of three interventions:

Session A (Receptive Music Therapy Intervention): 1) emotional checkin/assessment, 2) lyric analysis, and 3) music-facilitated relaxation. Session B (Expressive Music Therapy Intervention): 1) emotional checkin/assessment, 2) instrument play, and 3) singing.

Music therapy interventions generally require active engagement in music. For the purpose of this study, the term expressive music therapy intervention refers to musicmaking, whether vocal or instrumental. Under this condition, participants engaged in music through singing and instrument play with a variety of rhythm instruments. The term receptive music therapy intervention refers to engaging in music without active music-making. The participants who participated in the receptive MT group took part in 
lyric analysis, music-facilitated deep breathing, and progressive muscle relaxation exercises.

\section{Measures}

An adapted form of the K6 Distress Scale (Kessler et al, 2010) was used to measure level of distress before and after MT session. The K6 is an abbreviated form of the Kessler Psychological Distress Scale (K10), using six of the ten items on the original scale. The K6 has been used internationally as a brief screen to measure psychological distress (Kessler et al., 2010). It was developed specifically to fulfill the need for a very brief scale that could be used in the U.S. National Health Interview Survey, a national survey of about 50,000 households for gathering data on the health of the population. The survey has been carried out in the U.S. for over 50 years (Centers for Disease Control and Prevention, 2014; Harvard Medical School, 2005; Kessler et al, 2010).

The K6 Distress Scale was modified for use in this study (See Appendix A). There are a total of six items on the questionnaire. Prior to the modified K6 questionnaire, the participant was asked for name, age, and ethnic/cultural background. The next six items were based on the K6 Distress Scale and asked the participant to rate agreement or disagreement with the statements in question on a Likert scale (strongly disagree, disagree, neutral, agree, strongly agree). The statements were: "In this moment,

you feel so sad that nothing could cheer you up," "In this moment, you feel nervous," "In this moment, you feel hopeless," "In this moment, you feel that everything is an effort," "In this moment you feel worthless," "In this moment, you feel restless or fidgety." 


\section{Procedures}

Participants were recruited from monthly music therapy groups at two different women's shelters. An average of three participants in each group participated per monthly session, resulting in 13 participants total. The modified K6 questionnaire was administered before (PreK6) and after (PostK6) the music therapy sessions. The informed consent statement (see Appendix B) was given to each participant to read as well as summarized verbally by the MT-BC. The sessions were approximately an hour long and featured two alternating session structures in an ABAB format:

Session A (Receptive Music Therapy Intervention) consisted of 3 interventions: 1) emotional check-in, 2) lyric analysis, and 3) music-facilitated relaxation. Each component took around 20 minutes of time. The emotional check-in component served as a time of greeting and assessment and allowed the MT-BC to introduce music therapy services, set the therapeutic environment, and evaluate the clients' current emotional state. The MT-BC facilitated this component as a short active-listening exercise by utilizing a live performance of the song "Lean on Me" by Bill Withers. For the lyric analysis piece, the MT-BC provided copies of the lyrics to the Simon and Garfunkel song "I Am a Rock" and led a discussion of its content and meaning, focusing on applications to the clients' lives. Discussion questions centered on healthy and unhealthy coping skills as well as the interaction of isolation and abuse. The music-facilitated relaxation component consisted of the MT-BC playing a repetitive chord progression on the guitar while leading the clients through deep breathing and progressive muscle relaxation exercises, ending with listening to the MT-BC performing the song "Let It Be" by the Beatles. 
Session B (Expressive Music Therapy Intervention) consisted of 3 interventions: 1) emotional check-in, 2) instrument play, and 3) singing. As in Session A, each component was roughly 20 minutes in length. The emotional check-in segment was facilitated very similarly as with Session A. The MT-BC introduced music therapy services, set the therapeutic environment, and evaluated the clients' current emotional state. The MT-BC invited clients to join in instrument play and singing during the song "Lean on Me." For the instrument play component, the MT-BC led emotional expression through playing rhythm instruments, which was in turn facilitated into a rhythm circle experience. The MT-BC directed the clients to focus on the social connection and emotional expression aspects of this exercise. The rhythm circle experience ended with the MT-BC prompting the clients to continue playing instruments while also joining in singing the chorus of the song "Let It Be" by the Beatles. 


\section{CHAPTER IV \\ ANALYSIS OF THE DATA}

\section{Hypotheses and Purpose}

The focus of this study was to examine on a particular way that music therapy could help survivors of intimate partner abuse: specifically, in the area of decreasing distress. For this study, a board-certified music therapist provided expressive and receptive music therapy services to focus on how differing styles of MT would affect the distress levels of female survivors of domestic violence. It was believed that expressive music therapy would be more effective in decreasing distress levels for this population when compared to receptive music therapy.

\section{Results}

\section{Preliminary Analyses}

Independent-samples $t$-tests showed that Age $(t[4.95]=-.68, p=.53)$ and Length of Stay $(t[7]=1.14, p=.29)$ were not different between the receptive and expressive music therapy conditions. See the Table 1 for means and standard deviations. 
Table 1

Participants' Ages and Length of Current Stay at Domestic Violence Shelter

\begin{tabular}{llcrr}
\hline & Therapy Condition & $N$ & Mean & Std. Deviation \\
Age & Expressive & 4 & 28.25 & 4.031 \\
& Receptive & 5 & 32.40 & 12.837 \\
$\begin{array}{l}\text { Length of Stay } \\
\text { (Days) }\end{array}$ & Expressive & 5 & 16.80 & 14.394 \\
& Receptive & 4 & 8.25 & 4.031 \\
\hline
\end{tabular}

A chi-square test of association also showed that ethnicity did not significantly differ between the two types of music therapy, $\chi^{2}(2)=3.43, p=.18$. See Table 2 for the raw frequencies.

Table 2

Music Therapy Conditions and Participants' Ethnic/Cultural Backgrounds

\begin{tabular}{lcccc}
\hline $\begin{array}{c}\text { Music Therapy } \\
\text { Condition }\end{array}$ & Caucasian & $\begin{array}{c}\text { Ethnicity } \\
\text { African } \\
\text { American }\end{array}$ & Biracial & Total \\
Expressive & 1 & 3 & 1 & 5 \\
Receptive & 5 & 1 & 1 & 7 \\
Total & 6 & 4 & 2 & 12 \\
\hline
\end{tabular}




\section{Primary Analyses}

PreK6 and PostK6 scores were calculated by averaging all six items' scores in their respective surveys. A 2 (Music Therapy Condition: Expressive vs Receptive) x 2 (K6: Pre vs Post) repeated-measures ANOVA with a between-subjects factor was run. Table 3 shows the means and standard deviations. PreK6 $(M=2.50, S E=.15)$ scores were significantly higher before therapy than the PostK6 scores $(M=1.80, S E=.16)$ were after therapy, Wilk's $\Lambda=.37, F(1,11)=18.80, p=.001, \eta^{2}=.63$. There was not a significant main effect between the Expressive $(M 2.03, S E=.19)$ and Receptive $(M=$ $2.27, S E=.17)$ music therapy conditions, $F(1,11)=.92, p=.36, \eta^{2}=.08$. Both types of music therapy similarly reduced K6 scores from before therapy to after therapy, so no interaction was found between the pre- and post- K6 measure and the type of therapy, Wilk's $\Lambda=.97, F(1,11)=.29, p=.60, \eta^{2}=.03$.

Table 3

Means and Standard Deviations of PreK6 and PostK6 Scores

\begin{tabular}{ccccc}
\hline & $\begin{array}{c}\text { Music Therapy } \\
\text { Condition }\end{array}$ & $M$ & $S D$ & $N$ \\
PreK6 & Expressive & 2.33 & .56 & 6 \\
& Receptive & 2.67 & .51 & 7 \\
& Total & 2.51 & .54 & 13 \\
PostK6 & Expressive & 1.72 & .17 & 6 \\
& Receptive & 1.88 & .74 & 7 \\
& Total & 1.81 & .54 & 13 \\
\hline
\end{tabular}


A 2 (Repeated, Time of Test: Pre vs Post) x 6 (Repeated: Questions) x 2

(Between, Type of Therapy: Expressive vs Receptive Therapy) three-way repeatedmeasures ANOVA was run with a between subjects factor. Regardless of the questions or the type of therapy, the scores significantly decreased from the pretest $(M=2.50, S E=$ $1.5)$ to the posttest $(M=1.80, S E=1.6)$, Wilk's $\Lambda=.37, F(1,11)=18.80, p=.001, \eta^{2}=$ .63. Regardless of whether one analyzed pretest or posttest scores and/or expressive or receptive groups, there were significant differences between the six questions, Wilk's $\Lambda=$ $.16, F(5,7)=7.29, p=.01, \eta^{2}=.84$. The questionnaire item that focused on feeling that "everything was an effort" was rated significantly higher than the other questions, $p \leq$ .007. The item that asked the client about feeling "nervous" was marginally higher than feeling "helpless," $p=.09$. No other comparisons between the individual questions were statistically significant, $p \geq .17$. See Table 4 for the means and standard errors.

Table 4

Comparisons Between Individual Items on the Adapted K6 Questionnaire

Questions $\quad M \quad S E$

In this moment, you feel so sad that nothing could cheer you up. 1.857 .186

In this moment, you feel nervous. $\quad 2.065 .199$

In this moment, you feel hopeless. 165

In this moment, you feel that everything is an effort. 3.482 .306

In this moment, you feel worthless. $\quad 1.726 .248$

In this moment, you feel restless or fidgety. $2.095 \quad 240$ 
Regardless of whether one was considering the preK6/postK6 scores and/or the individual questionnaire items, scores were not statistically different between Receptive $(M=2.27, S E=.17)$ and Expressive therapy $(M=2.03, S E=.19), \mathrm{F}(1,11)=.92, p=.36$, $\eta^{2}=.08$. No significant interactions were found between pretest/posttest and the type of therapy (Wilk's $\Lambda=.97, F[1,11]=.29, p=.60, \eta^{2}=.03$ ), between the six questions and the type of therapy (Wilk's $\Lambda=.39, F[5,7]=2.71, p=.17, \eta^{2}=.61$ ), and between preK6/postK6 and the six items, Wilk's $\Lambda=.76, F(5,7)=.44, p=.80, \eta^{2}=.24$. The three-way interaction was also not statistically significant, Wilk's $\Lambda=.80, F(5,7)=.35, \mathrm{p}$ $=.87, \eta^{2}=.20$. See the following tables for the means and standard errors.

Table 5

Type of Therapy and Pretest/Posttest

Type of Therapy

Expressive Therapy

Posttest

Receptive Therapy
Pre/Posttest

M

$S E$

Pretest $\quad 2.67$

Posttest
2.33

1.72

1.88
.22

.23

.20 
Table 6

Type of Therapy and the Individual Questionnaire Items

\begin{tabular}{|c|c|c|c|c|}
\hline \multirow[b]{3}{*}{ Questions } & \multicolumn{4}{|c|}{ Type of Therapy } \\
\hline & \multicolumn{2}{|c|}{$\frac{\text { Expressive }}{\text { Therapy }}$} & \multicolumn{2}{|c|}{$\underline{\text { Receptive Therapy }}$} \\
\hline & $M$ & $S E$ & $M$ & $S E$ \\
\hline $\begin{array}{l}\text { In this moment, you feel } \\
\text { so sad that nothing could } \\
\text { cheer you up. }\end{array}$ & 1.50 & .27 & 2.21 & 0.25 \\
\hline $\begin{array}{l}\text { In this moment, you feel } \\
\text { nervous. }\end{array}$ & 1.92 & 0.29 & 2.21 & 0.27 \\
\hline $\begin{array}{l}\text { In this moment, you feel } \\
\text { hopeless. }\end{array}$ & 1.50 & 0.24 & 1.86 & 0.22 \\
\hline $\begin{array}{l}\text { In this moment, you feel } \\
\text { that everything is an } \\
\text { effort. }\end{array}$ & 3.75 & 0.45 & 3.21 & 0.42 \\
\hline $\begin{array}{l}\text { In this moment, you feel } \\
\text { worthless. }\end{array}$ & 1.67 & 0.36 & 1.79 & 0.34 \\
\hline $\begin{array}{l}\text { In this moment, you feel } \\
\text { restless or fidgety. }\end{array}$ & 1.83 & 0.35 & 2.36 & 0.33 \\
\hline
\end{tabular}


Table 7

Pretest/Posttest and the Individual Questionnaire Items

\begin{tabular}{|c|c|c|c|c|}
\hline \multirow[b]{2}{*}{ Questionnaire Items } & \multicolumn{2}{|c|}{$\underline{\text { Pretest }}$} & \multicolumn{2}{|c|}{ Posttest } \\
\hline & $M$ & $S E$ & $M$ & $S E$ \\
\hline $\begin{array}{l}\text { In this moment, you feel so } \\
\text { sad that nothing could cheer } \\
\text { you up. }\end{array}$ & 2.05 & .19 & 1.67 & 0.23 \\
\hline $\begin{array}{l}\text { In this moment, you feel } \\
\text { nervous. }\end{array}$ & 2.45 & .30 & 1.68 & 0.24 \\
\hline $\begin{array}{l}\text { In this moment, you feel } \\
\text { hopeless. }\end{array}$ & 2.06 & .21 & 1.30 & 0.80 \\
\hline $\begin{array}{l}\text { In this moment, you feel that } \\
\text { everything is an effort. }\end{array}$ & 3.93 & .28 & 3.04 & 0.42 \\
\hline $\begin{array}{l}\text { In this moment, you feel } \\
\text { worthless. }\end{array}$ & 2.07 & .34 & 1.38 & 0.19 \\
\hline $\begin{array}{l}\text { In this moment, you feel } \\
\text { restless or fidgety. }\end{array}$ & 2.44 & .36 & 1.75 & 0.26 \\
\hline
\end{tabular}


Table 8

Three-Way Interaction

\begin{tabular}{|c|c|c|c|c|}
\hline $\begin{array}{l}\text { Type of } \\
\text { Therapy }\end{array}$ & $\begin{array}{l}\text { PreK6/ } \\
\text { PostK6 }\end{array}$ & Questions & $M$ & $S E$ \\
\hline \multirow[t]{12}{*}{$\begin{array}{l}\text { Expressive } \\
\text { Therapy }\end{array}$} & \multirow[t]{6}{*}{ Pretest } & $\begin{array}{l}\text { In this moment, you feel so sad that nothing could } \\
\text { cheer you up. }\end{array}$ & 1.67 & .28 \\
\hline & & In this moment, you feel nervous. & 2.33 & .44 \\
\hline & & In this moment, you feel hopeless. & 1.83 & .31 \\
\hline & & In this moment, you feel that everything is an effort. & 4.00 & .41 \\
\hline & & In this moment, you feel worthless. & 2.00 & .50 \\
\hline & & In this moment, you feel restless or fidgety. & 2.17 & .53 \\
\hline & \multirow[t]{6}{*}{ Posttest } & $\begin{array}{l}\text { In this moment, you feel so sad that nothing could } \\
\text { cheer you up. }\end{array}$ & 1.33 & .33 \\
\hline & & In this moment, you feel nervous. & 1.50 & .36 \\
\hline & & In this moment, you feel hopeless. & 1.17 & .262 \\
\hline & & In this moment, you feel that everything is an effort. & 3.50 & .62 \\
\hline & & In this moment, you feel worthless. & 1.33 & .28 \\
\hline & & In this moment, you feel restless or fidgety. & 1.50 & .38 \\
\hline \multirow[t]{12}{*}{$\begin{array}{l}\text { Receptive } \\
\text { Therapy }\end{array}$} & \multirow[t]{6}{*}{ Pretest } & $\begin{array}{l}\text { In this moment, you feel so sad that nothing could } \\
\text { cheer you up. }\end{array}$ & 2.43 & .26 \\
\hline & & In this moment, you feel nervous. & 2.57 & .41 \\
\hline & & In this moment, you feel hopeless. & 2.29 & .28 \\
\hline & & In this moment, you feel that everything is an effort. & 3.86 & .38 \\
\hline & & In this moment, you feel worthless. & 2.14 & .47 \\
\hline & & In this moment, you feel restless or fidgety. & 2.71 & .49 \\
\hline & \multirow[t]{6}{*}{ Posttest } & $\begin{array}{l}\text { In this moment, you feel so sad that nothing could } \\
\text { cheer you up. }\end{array}$ & 2.00 & .31 \\
\hline & & In this moment, you feel nervous. & 1.86 & .33 \\
\hline & & In this moment, you feel hopeless. & 1.43 & .24 \\
\hline & & In this moment, you feel that everything is an effort. & 2.57 & .57 \\
\hline & & In this moment, you feel worthless. & 1.43 & .26 \\
\hline & & In this moment, you feel restless or fidgety. & 2.00 & .35 \\
\hline
\end{tabular}




\section{Summary}

Results showed that in general, music therapy had a significant effect on the distress levels of women living in a domestic violence shelter. Comparing preK6 and postK6 scores supported the idea that music therapy helped to decrease the distress of female victims of intimate partner violence. No significant difference was found between the effects of expressive or receptive music therapy either overall or when analyzing the individual questionnaire items. 


\title{
CHAPTER V \\ SUMMARY, CONCLUSIONS AND RECOMMENDATIONS
}

\begin{abstract}
Summary
The data suggest that music therapy may be an effective treatment for decreasing distress levels for women who have recently experienced abuse at the hands of a current or former intimate partner. It was originally thought that expressive music therapy (that is, music therapy facilitated in order to have the participants express themselves through singing, instrument play, and music making) would be more effective than receptive music therapy (e.g. music-facilitated relaxation and lyric analysis). However, there were no significant differences in the participant distress levels between the two types of music therapy. There was a significant decrease in participant distress levels when measured before and after music therapy sessions.
\end{abstract}

\section{Discussion}

\section{Discussion of Study Results}

Optimally, the researchers were aiming to have at least several dozen participants in this study. Due to time constraints and limitations at the study sites, data were only allowed to be gathered at four music therapy sessions, though the MT-BC who facilitated the study was able to lead twelve sessions total. The agency is dependent on a variety of 
grants, and was only able to allow monthly sessions at the two sites for a maximum of six months in order not to compromise grant status.

In the twelve sessions that the MT-BC facilitated at the study sites, there were various clinical observations that may have bearing on this study, even though no qualitative data was gathered. The MT-BC noted that during the expressive music therapy interventions (such as instrument play and singing), clients tended to display a brightened affect. Spontaneous laughter and dancing would sometimes occur during these exercises. During the receptive music therapy interventions (e.g. lyric analysis and music-facilitated relaxation), group members often became emotional. Many became tearful. However, according to the data gathered, there appeared to be no significant difference between the expressive and receptive groups for the questionnaire item focused on sadness (see the first questionnaire item, Appendix A). So even though the two groups expressed very different emotions from each other, both groups rated their levels of sadness very similarly. According to the data gathered, only one person in the receptive music therapy group self-rated an increase in sadness. There was a significant decrease in levels of sadness overall. Interestingly, what the MT-BC observed behaviorally (crying, tearfulness, etc.) was not reflected in the receptive music therapy group's questionnaire scores. In both groups, the item relating to sadness was rated relatively low, with participants indicating that they generally did not feel very sad in the moment.

Besides affect differences in the group, receptive groups tended to need more careful facilitation. If not conscientiously led, group lyric analysis exercises could result in the splintering of the group dynamic, with individual members being emotionally 
triggered by the others. This may have been due to choice of music literature. In the initial sessions, the MT-BC utilized the song "Three Things" by Jason Mraz for lyric analysis, as the lyrics lend themselves well to discussing healthy coping skills. However, one line in particular ("love is still the answer I'm relying on") tended to cause emotional reactions from group members. The group members would become almost defensive. When the MT-BC would frame that line of the song in a different way (e.g. "loving yourself" as opposed to love coming from someone else), the word "love" itself seemed to cause contention. The clients would be distracted by the word and all their associations with it, which was not necessarily therapeutically productive. Even when the word "love" was changed ("hope is still the answer I'm relying on"), the clients still appeared to have similar responses as before. When the song was switched with a song that did not directly address romantic relationships ("I Am a Rock" by Simon and Garfunkel), the group discussion was more easily kept on topic, and more therapeutic issues were discussed. Curiously, even though the substituted song also used the word "love," participants did not appear to respond in a defensive way. This could be due to the differences in the ways that the individual songs use the word "love." In "Three Things," the word "love" is treated in a very positive way. In "I Am a Rock," the word "love" is seen as something negative, both unwanted and unneeded.

There were a few confounding variables that were encountered in the course of this study. Due to the acute nature of the domestic violence shelters, there was no controlling for who would be in attendance in any given session. Some clients received both the expressive and receptive treatments. It is possible that perceptions may have been carried into a session from a previous session, affecting the results of the study. 
The music utilized in each session is also an interesting consideration. The same songs were used throughout the study for consistency, but an argument could be made that the results of the study were due to the music literature chosen by the MT-BC. It would be interesting to repeat this research study using different song choices. Knowing how influential certain songs were on the mood of the individual participants and how they affected the group dynamic, it is possible that different songs would achieve different results. Generally, staying away from songs that are romance-focused or that utilize romantic language is preferable for this population, as the subject is a complicated and often triggering one for individuals who have suffered intimate partner violence.

The skill level of the music therapist goes hand-in-hand with the importance of the music literature being used in the sessions. A music therapist with a different personality type or a different skill level at engaging clients could possibly have seen a much different outcome. This underlines the importance of the issue of the therapeutic relationship. In an acute setting, it takes clinical skill in order to build therapeutic rapport in just one session (as opposed to a series of sessions). A clinician with more or less skill in fostering a therapeutic relationship could have had a big impact on the study results.

Another confounding variable is that the MT-BC could not account for individual music preferences in this study. Due to the group setting and in order to keep as much consistency as possible between sessions, the same music literature was used throughout the study. If more flexibility in song choice had been used, the results of the study could have been very different.

Also to be considered is the fact that music therapy is often seen as an innovative form of treatment. It is different from other forms of therapy, and so participation in the 
session and relating to the facilitating MT-BC is a unique experience for many people. Some clients are more enthusiastic about participating in MT sessions due to this very novelty, while others may need more encouragement to try something so unfamiliar. Not only this, but different MT-BCs will facilitate in different ways. While all MT-BCs in the United States have met the minimum standard requirements and proficiencies as set forth by the American Music Therapy Association, there may still be vast differences between styles of facilitation. If this study were repeated by another MT-BC, the results could possibly be very different than the ones found here.

The K10 distress scale is the original form of the distress scale on which the K6 distress scale is based. The questionnaire used in this study (see Appendix A) was a modified form of the K6 distress scale. It was found that the Cronbach alpha for the prestudy K6 scores was .49 and .57 for the post-study K6 scores. The brevity and simplicity of the adapted K6 helped to increase participation in the study. However, the small number of items on the questionnaire may have decreased its internal reliability while increasing its user friendliness. In the future, this may be addressed by utilizing a questionnaire with more items as well as having more participants. A larger participant pool would also help to generalize findings. The results from this study support the idea that music therapy could be effective in reducing the distress levels of this population. Having additional support through further study with more participants and a more comprehensive questionnaire would help strengthen this position. 


\section{Addressing the Limitations of Related Studies}

As stated before, there is just not enough information in music therapy literature on the use of music therapy as a treatment for victims of domestic violence. Other populations have a plethora of research dedicated to them. That extensiveness is lacking in the area of researching music therapy treatments specific to the clinical needs of victims of intimate partner violence. This study helps to address the need for more research in this area.

Further, there is a deficiency in the amount of information about how music therapy could affect IPV/DV victims in an acute setting. The majority of the related studies that were examined for the literature review had participants who were able to participate in the study for several sessions in a row. There was very little in the literature about the effects of treatment in more acute settings. This study addressed this shortcoming by bringing music therapy to the acute setting of two domestic violence shelters for women. Due to the structure of the sessions (one session per site per month), there tended to be a great chance that the clients seen in one session would have already left the shelter by the time the next session occurred.

\section{How These Results Affect Clinical Practice in Music Therapy}

Considering the staggering consequences of intimate partner violence, treatment is essential for survivors of this type of abuse. Music therapists who work with this population must be informed of the urgent need for treatment, the unique clinical needs of the survivors, and the techniques that work. The transfer that can be made from the 
results of this study show that both expressive and receptive music therapy can help to decrease the distress levels of women living at a domestic violence shelter.

Music therapists should note that affect changes may or may not have actual bearing on the current emotional state of clients in this population. Clients who participated in expressive music therapy often displayed brightened affect and clients who participated in receptive music therapy often displayed a saddened affect. Even though the two groups appeared to display very different emotions, both rated their levels of sadness very similarly.

Another point to note is the importance of song choice. The literature used in this study was chosen carefully so as to avoid usage of songs that were overtly romantic. In previous experience with this population, it was found that using songs that utilized the word "love" in what could possibly be a romantic way was counterproductive in this setting. Victims of domestic violence often find the idea of romantic love to be an unwelcome reminder of what they have gone through. For women who are living in a domestic violence shelter, the trauma they experienced at the hands of their partner is very recent. Being in such a vulnerable emotional state makes them particularly susceptible to falling back into the state of mind that they were in at the time of the trauma. In an individual therapy session, the facilitator could possibly redirect the client into processing their thoughts in a productive way. However, in a group session, having one client mentally and emotionally revert back to her traumatic experience can draw the other clients into the same state. The results can be something of a train wreck: clients recounting the specific trauma(s) they suffered, reminding their peers about their specific trauma(s), and triggering everyone into reverting back to the traumatized state of mind. 
Instead of the group becoming a supportive, safe environment, the group dynamic is splintered into a non-therapeutic, non-beneficial environment in which the therapeutic focus is lost. Careful consideration must be given to the song choices used, especially for lyric analysis exercises, as well as how discussions questions are framed.

It is promising to see that the results of this study support the idea that both expressive and receptive music therapy are effective with this population. Distinct affect differences were noted between the two groups. The expressive music therapy group tended to have a more lighthearted feel, with participants smiling, laughing and sometimes even dancing. The receptive music therapy groups tended to be quieter and more introspective. Usually, song discussions resulted in participants becoming tearful. This is important to note for music therapists working with this population. Sessions

could be structured in a sort of "bell curve," beginning with something more lighthearted and less emotionally intrusive (such as instrument play), moving to interventions that require clients to give more personal insights (such as lyric analysis), and ending with something upbeat (such as singing and/or a rhythm circle). By combining the various types of music therapy, clinicians can avoid having emotionally one-sided sessions.

\section{How These Results Apply to the General Needs of This Population}

It is evident from reviewing the literature on domestic abuse that victims of this type of abuse suffer from many different types of issues. They may have issues resulting both directly and indirectly from the abuse. Mental health is of particular concern for survivors of IPV, who could be dealing with depression, suicidality, PTSD, substance abuse, and anxiety as a result of the abuse. Added to the list is the fiscally debilitating 
aftermath of domestic violence. Emergency room visits, doctors' appointments, physical therapy, dental care, paramedic services, outpatient visits, missed work days, and the cost of childcare can be financially crippling for survivors of IPV.

Victims of IPV are often left dealing with a physical, mental, emotional, and financial issues. The burden of it can be overwhelmingly distressing. Considering all of this, a multidimensional, non-threatening, expressive form of therapy could be very helpful for this population. Music therapy is unique in its ability to create a safe environment, its support of self-expression, its aptitude for increasing relaxation, and (as suggested by this study) its effectiveness in decreasing distress.

\section{Recommendations for Further Research}

This study could be improved upon in two ways: having a larger participant pool and a more reliable questionnaire for gathering data. Though the abuse agency allowed for twelve music therapy sessions, various circumstances only allowed four sessions for gathering data. A larger participant pool could be acquired through coordinating with a facility that is able to provide a longer period for gathering data. Even better would be to coordinate with several facilities that serve the domestic violence population. Another way to improve this study would have been to utilize mixed methods. With only 13 participants, combining both quantitative and qualitative research methods would have provided additional insight that could have enriched the findings of this study. The qualitative data could have also added understanding of the observed affect differences between groups. In future study, this qualitative component could be addressed by having a debriefing period at the end of the session. In this time, the facilitating MT-BC could 
ask clients about their overall thoughts about participating in the music therapy session, including what was helpful, what was not so helpful, and their general emotional state. Another area that could be addressed in further study is to control for repeat participants. Due to the completely anonymous nature of the questionnaire (a measure required by the facilities), it was not possible to track whether a participant had attended more than one music therapy session.

It would also be useful to conduct a further study comparing music therapy services with other forms of therapy, such as art therapy or general group verbal processing. In that way, comparisons could be drawn between the effectiveness of various therapy types. Originally, this study was planned to focus on the effectiveness of music therapy compared to the effectiveness of general group therapy in decreasing distress levels of women living at a battered women's shelter. Due to research ethic requirements and time limitations at the study sites, that aspect of the study was not able to be pursued. 


\section{REFERENCES}

American Psychological Association (2014). Intimate partner violence: Facts \& resources. Retrieved from http://www.apa.org/topics/violence/partner.aspx

Amir, D. (2004). Giving trauma a voice: The role of improvisational music therapy in exposing, dealing with and healing a traumatic experience of sexual abuse. Music Therapy Perspectives, 22(2), 96-103.

Beeble, M. L., Bybee, D., Sullivan, C. M., \& Adams, A. E. (2009). Main, mediating, and moderating effects of social support on the well-being of survivors of intimate partner violence across 2 years. Journal of Consulting and Clinical Psychology, 77(4), 718-729.

Block, C. R. (2003). How can practitioners help an abused woman lower her risk of death? NIJ Journal, (250), 4-7.

Borczon, R.M., Jampel, P., Langdon, G.S. (2010). Music therapy with adult survivors of trauma. In K. Stewart (Ed.), Music Therapy and Trauma: Bridging Theory and Clinical Practice (pp. 39-57). New York: Satchnote Press.

Calton, J. \& Cattaneo, L. B. (2014). The effects of procedural and distributive justice on intimate partner violence victims' mental health and likelihood of future helpseeking. American Journal of Orthopsychiatry, 84(4), 329-340.

Cassity, M. D. \& Theobold, K. A. K. (1990). Domestic violence: Assessments and treatments employed by music therapists. Journal of Music Therapy, 27(4), 179194.

Centers for Disease Control and Prevention [CDC]. (2003). Costs of intimate partner violence against women in the United States. Retrieved from http://www.cdc.gov/violenceprevention/pdf/IPVBook-a.pdf

Centers for Disease Control and Prevention [CDC]. (2012). National health interview survey. Retrieved from http://www.cdc.gov/nchs/nhis.htm.

Centers for Disease Control and Prevention, National Center for Injury Prevention and Control, Division of Violence Prevention [CDC]. (2010). NISVS: An overview of intimate partner violence in the United States - 2010 findings. Retrieved from http://www.cdc.gov/violenceprevention/pdf/ipv-nisvs-factsheet-v5-a.pdf 
Chan, K. L., Brownridge, D. A., Yan, E., Fong, D. Y. T., \& Tiwari, A. (2011). Child maltreatment polyvictimization: Rates and short-term effects on adjustment in a representative Hong Kong sample. Psychology of Violence, 1(1), 4-15. doi: $10.1037 / \mathrm{a} 0020284$

Coffman, D. D. \& Adamek, M. S. (1999). The contributions of wind band participation to quality of life of senior adults. Music Therapy Perspectives, 17(1), 27-31. doi: 10.1093/mtp/17.1.27

Cohen, S. \& Williamson, G. (1988). Perceived stress in a probability sample of the United States. In Spacapan, S. \& Oskamp, S. (Eds.)

Coker, A. L., Smith, P. H., McKeown, R. E., \& King, M. J. (2000). Frequency and correlates of intimate partner violence by type: Physical, sexual, and psychoogical battering. American Journal of Public Health, 90(4), 553-559.

Ellsberg, M. (1999). Domestic violence and emotional distress among Nicaraguan women. American Psychologist, 54(1), 30-36.

Follingstad, D. R., Rutledge, L. L., Berg, B. J., Hause, E. S., \& Polek, D. S. (1990). The role of emotional abuse in physically abusive relationships. Journal of Family Violence, 5(2), 107-120.

Hanson, N., Gfeller, K. E., Woodworth, G., Swanson, E. A., \& Garand, L. (1996). A comparison of the effectiveness of differing types and difficulty of music activities in programming for older adults with Alzheimer's disease and related disorders. Journal of Music Therapy, 33(2), 93-123.

Golding, J. M. (1999). Intimate partner violence as a risk factor for mental disorders: A meta-analysis. Journal of Family Violence, 14(2), 99-132.

Goodwin, S. N., Chandler, D., Meisel, J. (2004). Violence against women: The role of welfare reform, final report (Document No. 205792). Retrieved from https://www.ncjrs.gov/pdffiles1/nij/grants/205792.pdf

Harvard Medical School, 2005. K10 and K6 scales. Retrieved from http://www.hcp.med.harvard.edu/ncs/k6_scales.php

Herman, J. L. (1992). Complex PTSD: A syndrome in survivors of prolonged and repeated trauma. Journal of Traumatic Stress, 5(3), 377-391.

Herman, J.L. (1998). Recovery from psychological trauma. Psychiatry \& Clinical Neurosciences, 52 [Supplement], S145-S150.

Hernández-Ruiz, E. (2005). Effect of music therapy on the anxiety levels and sleep patterns of abused women in shelters. Journal of Music Therapy, 42(2), 140-158. 
Jewkes, R. (2002). Intimate partner violence: Causes and prevention. The Lancet, 359(9315), 1423-1429. doi: 10.1016/S0140-6736(02)08357-5

Kelly, J. B. \& Johnson, M. P. (2008). Differentiation among types of intimate partner violence: Research update and implications for interventions. Family Court Review, 46(3), 476-499.

Kessler, R. C., Green, J. G., Gruber, M. J., Sampson, N. A., Bromet, E., Cuitan, M., Farukawa, T. A., Gureje, O., Hinkov, H., Hu, C., Lara, C., Lee, S., Mneimneh, Z., Myer, L., Oakley-Browne, M., Posada-Villa, J., Sagar, R., Viana, M. C., \& Zaslavsky, A. M. (2010). Screening for serious mental illness in the general population with the K6 screening scale: results from the WHO World Mental Health (WMH) survey initiative. International Journal Methods in Psychiatric Research, 19(Supplement 1). 4-22. doi: 10.1002/mpr.310.

Kuhn, D. (2002). The effects of active and passive participation in musical activity on the immune system as measured by salivary immunoglobulin A (SIgA). Journal of Music Therapy, 39(1), 30-39.

Miller, L. E., Howell, K. H., \& Graham-Bermann, S. A. The effect of an evidence-based intervention on women's exposure to intimate partner violence. American Journal of Orthopsychiatry, 84(4), 321-328.

Montello, L. \& Coons, E. E. (1998). Effects of active versus passive group music therapy on preadolescents with emotional, learning, and behavioral disorders. Journal of Music Therapy, 35(1), 49-67.

National Institute of Justice (2007, October 24). Intimate partner violence. Retrieved from: http://www.nij.gov/topics/crime/intimate-partnerviolence/Pages/welcome.aspx

Nevada Network Against Domestic Violence [NNADV] (2012). Domestic violence handbook for victims \& professionals. Retrieved from http://www.nnadv.org/wpcontent/uploads/2013/01/DV-Handbook.pdf

Nolan, P. (2005). Special feature: Verbal processing within the music therapy relationship. Music Therapy Perspectives, 23(1), 18-28.

Peck, B. (2012) Treating adult trauma survivors. In L. L. Levers (Ed.), Trauma Counseling: Theories and Interventions. New York, NY: Springer Publishing Company, LLC.

Reed, G. L. \& Enright, R. D. (2006). The effects of forgiveness therapy on depression, anxiety, and posttraumatic stress for women after spousal emotional abuse.

Journal of Consulting and Clinical Psychology, 74(5), 920-929. doi: 10.1037/0022-006X.74.5.920 
Robb, S. (1996). Techniques in song writing: Restoring emotional and physical well being in adolescents who have been traumatically injured. Music Therapy Perspectives, 14(1), 30-37. doi: 10.1093/mtp/14.1.30

Seligman, M. E. P. (2008). Positive health. Applied Psychology: An International Review, 57, 3-18. doi: 10.1111/j.1464-0597.2008.00351.x

Seligman, M. E. P., Parks, A. C. \& Steen, T. (2004). A balanced psychology and a full life. Philosophical Transactions of the Royal Society, 359, 1379-1381.

Silverman, M. J. (2007). Evaluating current trends in psychiatric music therapy: A descriptive analysis. Journal of Music Therapy, 44(4), 388-414.

Stockton, H., Joseph, S., \& Hunt, N. (2014) Expressive writing and posttraumatic growth: An internet-based study. Traumatology: An International Journal, 20(2), 75-83. doi: http://dx.doi.org/10.1037/h0099377.

Takahashi, T. \& Matsushita, H. (2006). Long-term effects of music therapy on elderly with moderate/severe dementia. Journal of Music Therapy, 43(4), 317-333.

Teague, A. K., Hahna, N. D., \& McKinney, C. H. (2006). Group music therapy with women who have experienced intimate partner violence. Music Therapy Perspectives, 24(2), 80-86.

Tjaden, P. \& Thoennes, N. (2000). Extent, nature, and consequences of intimate partner violence. Retrieved from https://www.ncjrs.gov/pdffiles1/nij/181867.pdf

U.S. Department of Justice, Office on Violence Against Women. (n.d.). Domestic violence. Retrieved from http://www.justice.gov/ovw/domestic-violence\#dv

Whipple, J. \& Lindsey, R. S. (1999). Music for the soul: A music therapy program for battered women. Music Therapy Perspectives, 17(2), 61-67. doi: 10.1093/mtp/17.2. 
APPENDIX A

ADAPTED K6 DISTRESS SCALE

\begin{tabular}{|c|c|c|c|c|c|c|}
\hline Age: & & & & & & \\
\hline Ethnicity/Race & Caucasian & $\begin{array}{c}\text { African } \\
\text { American }\end{array}$ & Hispanic & $\begin{array}{l}\text { American } \\
\text { Indian or } \\
\text { Alaskan } \\
\text { Native }\end{array}$ & $\begin{array}{c}\text { Asian or } \\
\text { Pacific } \\
\text { Islander }\end{array}$ & Other \\
\hline $\begin{array}{c}\text { Please circle the } \\
\text { appropriate } \\
\text { number }\end{array}$ & $\begin{array}{l}\text { Strongly } \\
\text { Disagree }\end{array}$ & Disagree & Neutral & Agree & $\begin{array}{c}\text { Strongly } \\
\text { Agree }\end{array}$ & \\
\hline $\begin{array}{c}\text { In this moment, } \\
\text { you feel so sad that } \\
\text { nothing could cheer } \\
\text { you up }\end{array}$ & 1 & 2 & 3 & 4 & 5 & \\
\hline $\begin{array}{l}\text { In this moment, } \\
\text { you feel nervous }\end{array}$ & 1 & 2 & 3 & 4 & 5 & \\
\hline $\begin{array}{l}\text { In this moment, } \\
\text { you feel hopeless }\end{array}$ & 1 & 2 & 3 & 4 & 5 & \\
\hline $\begin{array}{l}\text { In this moment, } \\
\text { you feel that } \\
\text { everything is an } \\
\text { effort }\end{array}$ & 1 & 2 & 3 & 4 & 5 & \\
\hline $\begin{array}{l}\text { In this moment, } \\
\text { you feel worthless }\end{array}$ & 1 & 2 & 3 & 4 & 5 & \\
\hline $\begin{array}{l}\text { In this moment, } \\
\text { you restless or } \\
\text { fidgety }\end{array}$ & 1 & 2 & 3 & 4 & 5 & \\
\hline
\end{tabular}




\section{APPENDIX B \\ MUSIC THERAPY RESEARCH STUDY \\ CONSENT FORM}

Hello! My name is Kristiana Miner. I am a graduate student at Illinois State University and I am conducting a research study on the effect of different types of music therapy on levels of distress.

In order to participate in this study, you must be at least 18 years of age. We ask that you fill out one questionnaire at the before the music therapy session begins and another one at the end of the music therapy session. It will only take about 5-10 minutes to complete each questionnaire. Participation is completely optional, and refusal to take part involves no penalty or loss of benefits. You may skip questions you do not wish to answer or discontinue participation at any time. There is no compensation for participating or penalty for not participating. Participating or not participating has no effect on whether you may receive music therapy services. I will not be looking at the questionnaires or the signed consent forms until after the session is complete, so I will not know whether or not any individual participated in the study until after the music therapy session is done.

You may find it emotionally upsetting to be asked to rate your level of distress at this time. Again, you may skip questions you do not wish to answer or discontinue answering the questionnaire at any point. There will be no penalty or loss of benefits if you choose to stop answering the questionnaire. If participating in this study becomes emotionally distressing, we urge you to stop taking the questionnaire and to seek help from the staff members at this site and/or your local counseling service.

If you have any questions about participating in this study, please contact Dr. Andrea Crimmins at amcrimm@ilstu.edu or Kristiana Miner at kjminer@ilstu.edu. In addition, for questions about your rights and/or concerns about adverse effects due to this study, please contact the Research Ethics \& Compliance Office: (309) 438-2529 and/or rec@ilstu.edu. 